\title{
Cesarean delivery rates among family physicians versus obstetricians: a population-based cohort study using instrumental variable methods
}

\author{
Russell Eric Dawe MDiv MD, Jessica Bishop MSc MD, Amanda Pendergast BSc(Hons) MD, \\ Susan Avery BSc MD, Kelly Monaghan PhD MD, Norah Duggan BMedSc MD, \\ Kris Aubrey-Bassler MSc MD
}

\section{Abstract}

Background: Previous research suggests that family physicians have rates of cesarean delivery that are lower than or equivalent to those for obstetricians, but adjustments for risk differences in these analyses may have been inadequate. We used an econometric method to adjust for observed and unobserved factors affecting the risk of cesarean delivery among women attended by family physicians versus obstetricians.

Methods: This retrospective population-based cohort study included all Canadian (except Quebec) hospital deliveries by family physicians and obstetricians between Apr. 1, 2006, and Mar. 31, 2009. We excluded women with multiple gestations, and newborns with a birth weight less than $500 \mathrm{~g}$ or gestational age less than 20 weeks. We estimated the relative risk of cesarean delivery using instrumental-variable-adjusted and logistic regression.

Results: The final cohort included 776299 women who gave birth in 390 hospitals. The risk of cesarean delivery was $27.3 \%$, and the mean proportion of deliveries by family physicians was $26.9 \%$ (standard deviation $23.8 \%$ ). The relative risk of cesarean delivery for family physicians versus obstetricians was 0.48 (95\% confidence interval $[\mathrm{Cl}] 0.41-0.56)$ with logistic regression and $1.27(95 \% \mathrm{Cl}$ 1.02-1.57) with instrumental-variable-adjusted regression.

Interpretation: Our conventional analyses suggest that family physicians have a lower rate of cesarean delivery than obstetricians, but instrumental variable analyses suggest the opposite. Because instrumental variable methods adjust for unmeasured factors and traditional methods do not, the large discrepancy between these estimates of risk suggests that clinical and/or sociocultural factors affecting the decision to perform cesarean delivery may not be accounted for in our database.

esarean delivery is a valuable and often life-saving intervention. ${ }^{1}$ However, the rapid, widespread increase in its use has not been associated with improved health outcomes, and there are risks associated with the procedure. ${ }^{1-4}$ The World Health Organization has suggested a target cesarean delivery rate of $10 \%-15 \%$ or less, ${ }^{5}$ which is exceeded by many countries, including Canada $(27 \%){ }^{6}$ Therefore, investigation into the factors that contribute to lower cesarean delivery rates are increasingly of interest. ${ }^{7}$

Some authors have found family physicians to have cesarean delivery rates that are lower than ${ }^{8-10}$ or equivalent to ${ }^{11}$ those for obstetricians. Although those studies all controlled for differences in measured risk factors for cesarean delivery, the results may still be explained by incomplete adjustment for family physicians' low-risk patient population. ${ }^{11}$ However, other authors have suggested that marginalized populations may preferentially chose to have a family physician attend the birth, thereby increasing the risk profile of the family physician patient population for different reasons. ${ }^{7,11}$ It is also possible that some types of provider are more diligent at coding the risk factors of their patients, confounding research that depends on such documentation.

Some authors have compared cesarean delivery rates by limiting the population studied to low-risk patients. ${ }^{9}, 12,13$ This creates a more homogeneous cohort, which is more easily studied but is less representative of the wider population. There is a need, therefore, for a method of analysis that can

\section{Competing interests: None declared.}

This article has been peer reviewed.

Correspondence to: Russell Dawe, r.dawe@mun.ca

CMAJ Open 2017. DOI:10.9778/cmajo.20170081 
accommodate the entire population served, and this is what the instrumental variable approach provides. Instrumental variable adjustment acts like a "natural randomization of patients"14 into cohorts with differing probabilities of receiving the treatment of interest, thereby decreasing heterogeneity across the treatment groups. For these reasons, instrumental variable methods are preferred when residual or unmeasured confounders may affect results such as for the study question addressed in the current study (cesarean delivery rates among family physicians versus obstetricians). Estimates from instrumental variable and traditional methods are usually similar; however, despite meeting all of the necessary criteria to use instrumental variable methods, we found a large, unexpected discrepancy between our results, with traditional analyses suggesting the expected lower rate of cesarean delivery among family physicians and instrumental variable analyses suggesting the opposite. This large discrepancy therefore became the focus of this paper rather than arguing for the increased accuracy of the instrumental variable results, as originally intended.

\section{Methods}

\section{Study design, data sources and population}

We accessed maternal and neonatal Discharge Abstract Database records from the Canadian Institute for Health Information. This database captures clinically significant diagnoses with high sensitivity and specificity ${ }^{15,16}$ and has been used for numerous studies of obstetrical outcomes. ${ }^{4,17-25}$ We linked records to Statistics Canada census socioeconomic information using the maternal 6-digit postal code, released in a 2 -step process to protect privacy (Appendix 1, available at www.cmajopen.ca/content/5/4/E823/suppl/DC1), and the Postal Code Conversion File. ${ }^{26}$ Multiple gestations and infants with a birth weight less than $500 \mathrm{~g}$ or gestational age less than 20 weeks at delivery were excluded. ${ }^{27,28}$

\section{Setting}

This analysis was conducted on data collected for another study of births between Apr. 1, 2006, and Mar. 31, 2009, at all Canadian hospitals except those in Quebec. ${ }^{29}$ Primary and repeat cesarean delivery rates have remained stable, at $18.5 \%$ and $82.4 \%$, respectively, in $2008 / 09$, compared with $18.8 \%$ and $81 \%$ in $2015 / 16{ }^{30}$ Therefore, we feel this study's data should still be applicable today.

\section{Record linkage and group assignment}

We linked neonatal records to the corresponding maternal record to adjust for perinatal factors that may have affected the decision to perform cesarean delivery. Linkage was conducted with the use of a variable provided by the Canadian Institute for Health Information or through probabilistic linkage using additional variables. Infant records that could not be matched to a single woman were excluded. Our database included 10 variables to record the types of care providers and their roles. We assigned records to the family physician group if a family physician was coded at any point as the most responsible provider. Deliveries by midwives were designated in a similar fashion but were excluded from the analysis because the sample size was insufficient to obtain precise results with the use of the primary statistical method. This classification appropriately assigns women for whom delivery by a family physician was planned but who experienced intrapartum complications necessitating transfer to an obstetrician or other provider (e.g., for cesarean delivery). However, this approach may bias against family physicians in some hospitals where care is shared between family physicians and obstetricians; in those models, women at high risk (and the higher cesarean rate) for whom delivery by an obstetrician is planned are often admitted under the family physician. The remaining women were categorized into the obstetrician group if the delivery provider was an obstetrician. All remaining records were excluded. We conducted sensitivity analyses testing different methods of group assignment and stratifying the cohort by whether they had had a prior cesarean delivery.

\section{Instrumental variable analysis}

Instrumental-variable-adjusted regression is an econometric technique that adjusts for unmeasured confounding variables in observational studies. An instrumental variable predicts the receipt of treatment (e.g., delivery by family physician) but is not directly associated with outcomes (e.g., cesarean delivery), except through its effect on treatment. In contrast, confounding variables are associated with both the receipt of treatment and outcomes.

For this study, we looked at the women living within the catchment area of each local hospital and took the instrumental variable to be the proportion of those women whose baby was delivered by a family physician. ${ }^{14,29}$ Thus, we assumed that living in an area with a relatively high frequency of delivery by family physician increases the likelihood of delivery by a family physician (treatment) without directly acting as a risk factor for cesarean delivery (outcome) itself. This is the same instrumental variable that has previously been used effectively in obstetrical ${ }^{29}$ and cardiac $^{14}$ studies. Institutional culture may influence cesarean delivery rates and may itself be influenced by the proportion of delivery providers who are family physicians; however, this association is not clear. If this association between family physicians, institutional culture and cesarean rates is real, this would violate the assumptions necessary for instrumental variable analyses. However, because the association is small, if any, we feel that it is unlikely to explain the large difference between the results from conventional and instrumental variable analyses outlined below.

To appropriately adjust for unmeasured variables, the instrumental variable must not be directly associated with them. Because these variables are unmeasured, it is not possible to verify this requirement. However, it is customary in instrumental variable studies to compare measured variables to ensure relative consistency across categories of the instrumental variable and to assume that unmeasured variables vary in a similar fashion. For additional discussion regarding instrumental variable techniques, see Appendix 1. 


\section{Hospital catchment areas}

We defined hospital catchment areas using methods developed and widely used by the Dartmouth Atlas Project for comparative health services research in the United States. ${ }^{31}$ Postal codes were assigned to a hospital if a plurality of patients living within the postal code were admitted to that hospital for their acute inpatient care. We used all (not just obstetrical) visits to acute care hospitals for the study period to assign patient postal codes to a hospital.

\section{Study outcome}

The study outcome was the relative risk of cesarean delivery among women managed primarily by family physicians compared to those managed by obstetricians. Cesarean deliveries were identified if any of the procedure variables included the Canadian Classification of Interventions ${ }^{32}$ code 5.MD.60. If family physicians were less comfortable performing procedural vaginal deliveries (vacuum- and forceps-assisted delivery) than obstetricians, this might increase their likelihood of choosing cesarean delivery. We therefore analyzed the rate of procedural vaginal delivery and of all procedural deliveries as secondary outcomes. The additional codes included in this outcome were 5.MD.53-55. For information on hospital service level and other covariates, see Appendix 1.

\section{Statistical analysis}

The primary statistical approach used the generalized method of moments to estimate multiplicative structural mean models with published Stata syntax. ${ }^{33}$ The most straightforward application of instrumental variable methods, 2-stage least-squares, applies similar concepts as our instrumental variable approach and therefore may help illustrate our method. In 2-stage leastsquares approach, the first stage is a conventional regression analysis, but with the treatment of interest (rather than the outcome) as the dependent variable. The first stage of the 2 -stage least-squares approach is equivalent to deriving a propensity score. The predicted probability of receiving the treatment of interest for each patient is then calculated from the first-stage regression, and this probability is entered as a covariate in the second-stage regression, which has the outcome of interest as the dependent variable. Instrumental variable methods are described in plain language elsewhere. ${ }^{34}$ The generalized method of moments is thought to be the most robust method of estimation for instrumental variable models with a dichotomous outcome and a continuous instrumental variable. ${ }^{33,35} \mathrm{We}$ also used logistic regression for comparison purposes, and we estimated risk ratios from these models as described previously. ${ }^{36}$ Analyses were conducted with the use of Stata version 13.1, and all models were adjusted for clustering at the hospital level.

\section{Ethics approval}

Ethics approval was granted by the Memorial University Human Investigations Committee. Data release was guided by the privacy regulations of the ethics board and of the Canadian Institute for Health Information. Patient consent was not required.

\section{Results}

The study cohort and exclusions are outlined in Figure 1. The final cohort included 776299 women who gave birth in 390 hospitals. The risk of cesarean delivery was $27.3 \%$, and the mean proportion of deliveries by family physicians was $26.9 \%$ (standard deviation 23.8\%). Table 1 presents selected characteristics of the study population, including the unadjusted cesarean delivery rates, by provider type. The differences between the family physician and obstetrician groups for most of these variables was small, with the exception of the rate of prior cesarean delivery and the annual mean provider delivery volume (67.3 for family physicians, 266.3 for obstetricians). All comparisons showed that obstetricians cared for a higher-risk population than did family physicians. Table 2 presents selected characteristics of the delivery providers, hospitals and women across family physician delivery quintiles at the home hospital.

The main study findings are presented in Table 3. Logistic regression estimates suggest that women cared for by family physicians had a lower risk of cesarean delivery, whereas the findings from instrumental-variable-adjusted analyses suggested the opposite, and both results were statistically significant. Table 3 also shows that the rate of forceps- and vacuumassisted delivery were equivalent between the 2 groups, which

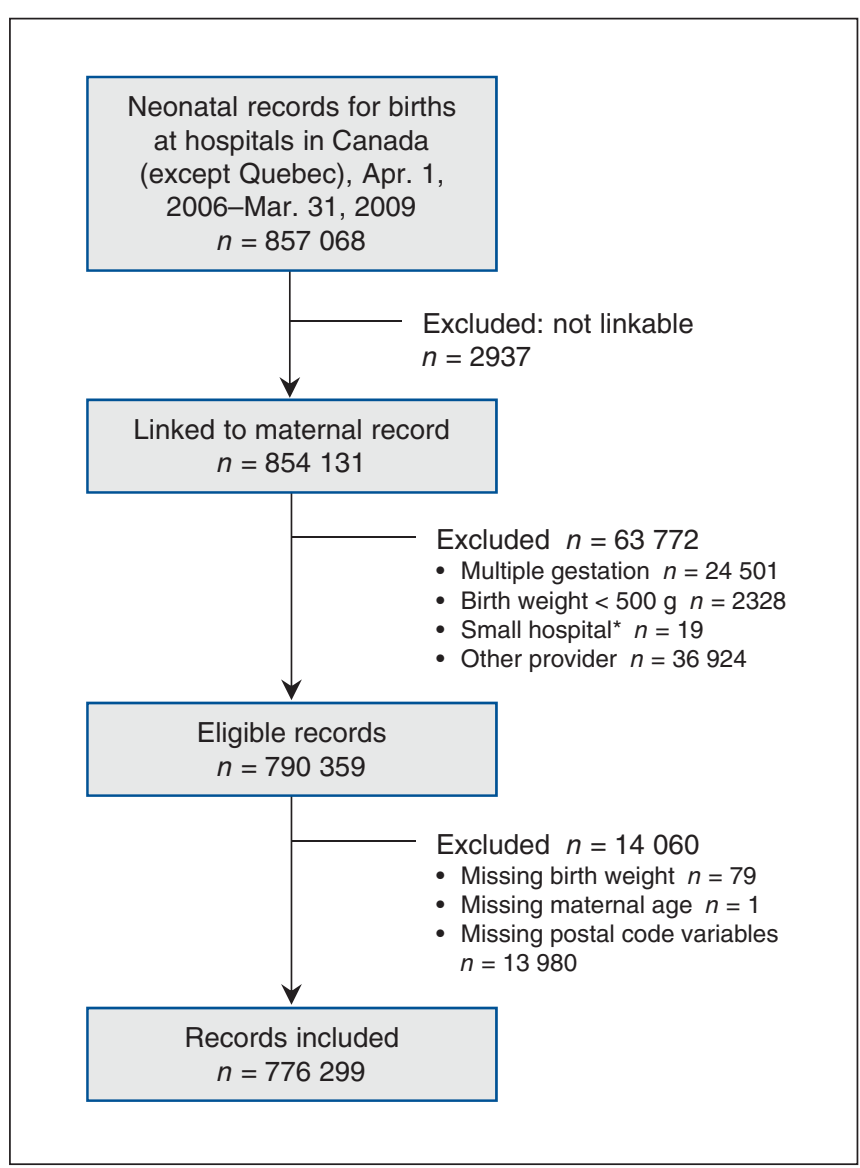

Figure 1: Flow diagram showing cohort selection. *Hospitals with fewer than 20 cesarean deliveries performed in women living within their catchment area. 
Table 1: Selected characteristics of women who gave birth between Apr. 1, 2006, and Mar. 31, 2009, at all Canadian hospitals except those in Quebec, by delivery provider

\begin{tabular}{|c|c|c|}
\hline \multirow[b]{2}{*}{ Characteristic } & \multicolumn{2}{|c|}{ Provider; no. (\%) of women* } \\
\hline & $\begin{array}{c}\text { Family } \\
\text { physician } \\
n=217870\end{array}$ & $\begin{array}{l}\text { Obstetrician } \\
n=558429\end{array}$ \\
\hline Cesarean delivery & $24830(11.4)$ & $192360(34.4)$ \\
\hline Age, mean $\pm S D$, yr & $28.2 \pm 5.6$ & $29.6 \pm 5.7$ \\
\hline Income, mean \pm SD, $\$$ & $26821 \pm 8827$ & $27777 \pm 9250$ \\
\hline $\begin{array}{l}\% \text { of women in census } \\
\text { subdivision with at least } \\
\text { some high school, mean } \\
\pm \text { SD }\end{array}$ & $81.7 \pm 14.1$ & $84.0 \pm 12.5$ \\
\hline Urban residence† & $151459(69.5)$ & $474695(85.0)$ \\
\hline \multicolumn{3}{|l|}{ Hospital level } \\
\hline 3 & $53901(24.7)$ & $150098(26.9)$ \\
\hline 2 & $77640(35.6)$ & $298269(53.4)$ \\
\hline 1 & $85642(39.3)$ & $110051(19.7)$ \\
\hline Prior cesarean delivery & 11229 (5.2) & 89265 (16.0) \\
\hline Type 1 diabetes & $89(0.04)$ & $1945(0.3)$ \\
\hline Type 2 diabetes & $167(0.1)$ & $2201(0.4)$ \\
\hline Gestational diabetes & $7280(3.3)$ & 29059 (5.2) \\
\hline Eclampsia & $96(0.04)$ & $374(0.1)$ \\
\hline Placental abruption & $176(0.1)$ & $1111(0.2)$ \\
\hline $\begin{array}{l}\text { Premature rupture of } \\
\text { membranes }\end{array}$ & $697(0.3)$ & $3660(0.6)$ \\
\hline Placenta previa & $362(0.2)$ & $3065(0.5)$ \\
\hline Genital herpes & $236(0.1)$ & $848(0.2)$ \\
\hline $\begin{array}{l}\text { Gestational age, mean } \\
\pm \text { SD, wk }\end{array}$ & $39.3 \pm 2.0$ & $38.8 \pm 2.3$ \\
\hline Birth weight, mean $\pm S D$, g & $3463 \pm 501$ & $3375 \pm 582$ \\
\hline Congenital anomaly & $4658(2.1)$ & 18779 (3.4) \\
\hline
\end{tabular}

indicates that a lack of comfort with forceps and vacuum does not explain the increased cesarean delivery rate among family physicians.

\section{Strength of instrumental variable}

Our instrumental variable predicted a wide range in the mean proportion of deliveries by a family physician $(4.3 \%-69.1 \%$ across quintiles). Although there are differences in measured covariates across the quintiles (Table 2), there was no correlation between catchment area cesarean delivery rate and the instrumental variable $\left(r^{2}=6.6 \times 10^{-4}\right)$, a required characteristic to ensure unbiased results. The F-statistic for our instrumental variable $(F=1165.94)$ far exceeded the Stock-Yogo "critical value" necessary to define a strong instrument. ${ }^{37}$ The partial correlation coefficient between the delivery provider and instrumental variable was 0.55 , which indicated that $30 \%$ of the varia- tion in the rate of delivery by family physicians was explained by the instrumental variable, also a marker of a strong instrument.

\section{Sensitivity analyses}

We compared multivariate models that both included and excluded variables for the service level of the delivery hospital. We also compared models with different definitions of delivery provider, including assigning women solely to the practitioner coded as the most responsible provider or to the practitioner coded as the delivery provider. None of these adjustments changed the direction of the estimated effects (risk ratio $>1.0$ or $<1.0$ ) or the statistical significance of the association (data not shown).

We stratified the sample according to prior cesarean delivery and repeated our analyses. For women with no prior cesarean delivery, the instrumental-variable-adjusted relative risk of cesarean delivery was 1.30 (95\% confidence interval [CI 1.04 1.64) for family physicians versus obstetricians. For women with a prior cesarean delivery, the relative risk was $0.96(95 \%$ CI 0.84-1.09), which suggests that the results of our primary analysis are entirely driven by a higher risk of first cesarean delivery. However, because women with a prior cesarean delivery appear to be selectively cared for by obstetricians (Table 1), the assumptions necessary for instrumental variable analyses may not be met when the sample is stratified in this fashion.

\section{Interpretation}

The results of our conventional analysis suggesting a lower risk of cesarean delivery among women cared for by family physicians are broadly comparable to the existing literature. However, the most striking finding of our study is the large discrepancy between these traditional results and those from instrumental variable methods, which suggest that women cared for by family physicians actually have a higher risk of cesarean delivery than those cared for by obstetricians, after adjustment for both measured and unmeasured risks. We feel that instrumental variable methods are the most appropriate to answer our research question because they address criticisms from previous work: that unmeasured factors contribute to observed differences in cesarean delivery rates between family physicians and obstetricians. $^{8-11}$ However, because of the novelty and magnitude of our findings and because of the methodological limitations outlined below, our findings require confirmation before a clinical or policy response should be considered.

Our adjustment for both clinical and demographic risk factors is at least as comprehensive as if not more comprehensive than (e.g., by including employment rate, visible minority status and Aboriginal status) previous obstetrics studies using the same database. ${ }^{17,19-22}$ Thus, we feel that we have met the currently accepted standard for the degree of adjustment necessary in the analysis of obstetrical data, but our results suggest that this degree of adjustment is inadequate. Clearly, this raises concerns that other studies relying on administrative data suffer from similar biases as our own. However, a recently published analysis of the same data and instrumental variable used in the current paper showed that the estimates 


\begin{tabular}{|c|c|c|c|c|c|c|}
\hline \multirow[b]{2}{*}{ Characteristic } & \multicolumn{6}{|c|}{ Quintile of family physician delivery rate; no. $(\%)^{*}$} \\
\hline & $n=148059$ & $\begin{array}{c}2 \\
n=158593\end{array}$ & $\begin{array}{c}3 \\
n=160518\end{array}$ & $\begin{array}{c}4 \\
n=151206\end{array}$ & $\begin{array}{c}5 \\
n=157923\end{array}$ & $\begin{array}{c}\text { All } \\
n=776299\end{array}$ \\
\hline Missing data† & $1766(1.2)$ & $2207(1.4)$ & $2400(1.5)$ & $4726(3.1)$ & $2980(1.9)$ & $14079(1.8)$ \\
\hline $\begin{array}{l}\text { Predicted cesarean delivery } \\
\text { rate, mean } \pm \text { SD } \ddagger\end{array}$ & $28.4 \pm 22.7$ & $28.9 \pm 22.7$ & $27.8 \pm 22.4$ & $27.8 \pm 22.6$ & $27.1 \pm 22.7$ & $28.0 \pm 22.7$ \\
\hline Income, mean $\pm \mathrm{SD}, \$$ & $27222 \pm 8581$ & $28601 \pm 10314$ & $28408 \pm 9175$ & $26604 \pm 8438$ & $26632 \pm 8822$ & $27509 \pm 9144$ \\
\hline$\%$ Aboriginal, mean \pm SD & $3.6 \pm 13.9$ & $2.4 \pm 8.8$ & $5.8 \pm 15.2$ & $5.9 \pm 14.4$ & $10.9 \pm 22.7$ & $5.8 \pm 15.9$ \\
\hline \multicolumn{7}{|l|}{ Delivery hospital } \\
\hline Level 3 & $13896(9.4)$ & $39481(24.9)$ & $60043(37.4)$ & 53996 (35.7) & $36583(23.2)$ & 203999 (26.3) \\
\hline Annual volume, mean \pm SD & $2626 \pm 1548$ & $3579 \pm 1665$ & $2936 \pm 1567$ & $3462 \pm 2260$ & $2016 \pm 1988$ & $2923 \pm 1913$ \\
\hline \multicolumn{7}{|l|}{ Delivery provider } \\
\hline Annual volume, mean \pm SD & $269 \pm 131$ & $260 \pm 151$ & $252 \pm 210$ & $176 \pm 150$ & $96 \pm 103$ & $210 \pm 167$ \\
\hline Obstetrician & $141732(95.7)$ & $144028(90.8)$ & $133475(83.2)$ & $90462(59.8)$ & $48732(30.8)$ & 558429 (71.9) \\
\hline Family physician & $6327(4.3)$ & $14565(9.2)$ & $27043(16.8)$ & $60744(40.2$ & $109191(69.1)$ & $217870(28.1)$ \\
\hline Midwife† & $5938(4.0)$ & $7621(4.8)$ & $7273(4.5)$ & $5657(3.7)$ & $4743(3.0)$ & $31232(4.0)$ \\
\hline \multicolumn{7}{|l|}{ Maternal } \\
\hline Age, mean $\pm S D$, yr & $29.3 \pm 5.7$ & $30.5 \pm 5.5$ & $29.0 \pm 5.6$ & $29.3 \pm 5.7$ & $28.2 \pm 5.7$ & $29.2 \pm 5.7$ \\
\hline $\begin{array}{l}\% \text { of women in census } \\
\text { subdivision with at least some } \\
\text { high school, mean } \pm \text { SD }\end{array}$ & $83.0 \pm 12.7$ & $86.5 \pm 11.2$ & $83.4 \pm 12.8$ & $83.5 \pm 12.4$ & $80.2 \pm 15.1$ & $83.3 \pm 13.0$ \\
\hline Urban residence & $128533(86.8)$ & $147590(93.1)$ & 136309 (84.9) & $118755(78.5)$ & $94967(60.1)$ & $626154(80.6)$ \\
\hline Cesarean delivery & $42010(28.4)$ & $45214(28.5)$ & 43585 (27.2) & $42212(27.9)$ & $44169(28.0)$ & $217190(28.0)$ \\
\hline Prior cesarean delivery & $19454(13.1)$ & $21011(13.2)$ & $20084(12.5)$ & $19472(12.9)$ & $20473(13.0)$ & 100494 (12.9) \\
\hline Type 1 diabetes & $429(0.3)$ & $390(0.2)$ & $471(0.3)$ & $373(0.2)$ & $371(0.2)$ & $2034(0.3)$ \\
\hline Type 2 diabetes & $409(0.3)$ & $449(0.3)$ & $615(0.4)$ & $404(0.3)$ & $491(0.3)$ & $2368(0.3)$ \\
\hline Gestational diabetes & $6595(4.4)$ & $8107(5.1)$ & $6515(4.0)$ & $8775(5.8)$ & $6347(4.0)$ & 36339 (4.7) \\
\hline Eclampsia & $120(0.05)$ & $89(0.1)$ & $102(0.1)$ & $62(0.04)$ & $97(0.1)$ & $470(0.1)$ \\
\hline $\begin{array}{l}\text { Pregnancy-induced } \\
\text { hypertension }\end{array}$ & $8430(5.7)$ & $8481(5.3)$ & $10381(6.5)$ & $9292(6.1)$ & $10046(6.4)$ & $46630(6.0)$ \\
\hline HIV-positive & $76(0.05)$ & $81(0.05)$ & $100(0.1)$ & $118(0.1)$ & $63(0.04)$ & $438(0.05)$ \\
\hline Placental abruption & $185(0.1)$ & $166(0.1)$ & $469(0.3)$ & $250(0.2)$ & $217(0.1)$ & $1287(0.2)$ \\
\hline $\begin{array}{l}\text { Premature rupture of } \\
\text { membranes }\end{array}$ & $414(0.3)$ & $387(0.2)$ & $2143(1.3)$ & $939(0.6)$ & $474(0.3)$ & $4357(0.6)$ \\
\hline \multicolumn{7}{|l|}{ Neonatal } \\
\hline Male sex & $75785(51.2)$ & $81326(51.3)$ & $82248(51.2)$ & $77872(51.5)$ & 80902 (51.2) & $398133(51.3)$ \\
\hline $\begin{array}{l}\text { Gestational age, mean } \\
\pm \mathrm{SD} \text {, wk }\end{array}$ & $38.9 \pm 2.2$ & $38.9 \pm 2.0$ & $38.9 \pm 2.4$ & $38.9 \pm 2.1$ & $39.1 \pm 2.5$ & $38.9 \pm 2.2$ \\
\hline Birth weight, mean $\pm S D, g$ & $3382 \pm 566$ & $3360 \pm 557$ & $3417 \pm 567$ & $3393 \pm 556$ & $3443 \pm 557$ & $3399 \pm 562$ \\
\hline Congenital anomaly & $4423(3.0)$ & $4502(2.8)$ & $5227(3.2)$ & $4906(3.2)$ & $4379(2.8)$ & $23437(3.0)$ \\
\hline Perinatal mortality & $686(0.5)$ & $700(0.4)$ & $597(0.4)$ & $628(0.4)$ & $600(0.4)$ & $3211(0.4)$ \\
\hline
\end{tabular}

from logistic and instrumental-variable-adjusted analyses of a perinatal mortality outcome were essentially identical and that those for maternal morbidity and mortality were much closer than the results observed in the current study. ${ }^{29}$ This suggests that the observed variables adequately capture the variance for perinatal mortality and come close to doing so for the 


\begin{tabular}{|c|c|c|c|}
\hline \multicolumn{4}{|c|}{$\begin{array}{l}\text { Table 3: Relative risk of cesarean delivery, forceps- or vacuum-assisted vaginal } \\
\text { delivery and all procedural deliveries for family physicians versus obstetricians on } \\
\text { logistic and instrumental-variable-adjusted regression }\end{array}$} \\
\hline \multirow[b]{2}{*}{ Method } & \multicolumn{3}{|c|}{$\mathrm{RR}(95 \% \mathrm{Cl})$} \\
\hline & Cesarean delivery & $\begin{array}{l}\text { Forceps- or } \\
\text { vacuum-assisted } \\
\text { vaginal delivery }\end{array}$ & $\begin{array}{l}\text { All procedural } \\
\text { deliveries }\end{array}$ \\
\hline \multicolumn{4}{|c|}{ Logistic regression } \\
\hline Bivariate & $0.33(0.27-0.40)$ & $1.02(0.91-1.13)$ & $0.35(0.31-0.40)$ \\
\hline Multivariate* & $0.48(0.41-0.56)$ & $1.00(0.92-1.09)$ & $0.61(0.56-0.67)$ \\
\hline \multicolumn{4}{|c|}{$\begin{array}{l}\text { Instrumental-variable- } \\
\text { adjusted regression }\end{array}$} \\
\hline Bivariate & $0.96(0.79-1.17)$ & $0.92(0.74-1.12)$ & $0.94(0.82-1.09)$ \\
\hline Multivariate* & $1.27(1.02-1.57)$ & $1.03(0.82-1.29)$ & $1.16(0.99-1.35)$ \\
\hline
\end{tabular}

maternal outcome. Thus, the limitations of the database may extend only to the analysis of highly complex treatment decisions such as cesarean delivery that depend not only on clinical factors but also possibly on patient factors, institutional culture and professional training, among others.

At least 2 clinical studies have compared the results from traditional and instrumental-variable-adjusted methods of observational analysis to those from randomized controlled trials. In both studies, results from instrumental variable analysis agreed closely with those from randomized controlled trials, while differing considerably from results obtained using traditional methods. ${ }^{14,38}$ In both of those studies, unmeasured factors affected the treatment decision, thereby biasing the estimates from traditional methods and showing the benefit instrumental variable techniques may offer.

\section{Limitations}

There are limitations to the instrumental variable approach. Although this type of analysis has been used in the econometrics literature for almost 90 years, it is relatively new to epidemiologists, and clinical applications may require further testing and refinement. As a new tool, it is not as well understood and may not be as readily accepted as more traditional methods, especially when the results differ in a potentially controversial manner, as in the present case. Nevertheless, this also highlights the need for this tool and its potential to address the limitations of traditional approaches.

Although the differences in the distribution of risk factors are usually small, we found that obstetricians care for a higher-risk population than family physicians. If these risk factors are not fully adjusted for in logistic analyses, here or in previous studies, the risk estimated for these populations may be biased. However, the risk factors outlined in Table 1 are traditional obstetrical comorbidities. Family physicians may care for populations that are higher risk owing to sociocultural and other reasons, ${ }^{7,11}$ and these variables are not captured in the administrative data used for this study (Appendix 1). If this is the case, unobserved factors that affect treatment decisions would be unevenly distributed between the experimental groups in our study, which would violate the assumptions required for instrumental variable analyses (i.e., instrumental-variable-adjusted analyses may be biased). Regardless of which estimates are biased, the underlying issue is that important covariates, whether clinical or sociocultural, are incompletely captured in the linked administrative, census and geographic data used for this study, which biases the estimates from 1 or both analytical methods used. Results of analyses of cesarean delivery rates using either of these methods should be interpreted cautiously until it can be established whether conventional or instrumental variable methods are inaccurate.

A further limitation is the incomplete randomizing effect of the instrumental variable across our women. Among the most important factors affecting the decision to perform a cesarean delivery is a prior cesarean birth, and these rates were similar across different levels of the instrumental variable (Table 2). However, we found several variables that did differ across instrumental variable quintiles, and this variation raises the possibility that unobserved variables also differ between levels of the instrumental variable. For example, the Aboriginal representation across quintiles ranged from $2.4 \%-10.9 \%$. Our data (not shown) indicate that cesarean delivery rates are lower in populations with higher proportions of Aboriginal women, but we adjusted for this factor in our multivariate analyses. This observation is only important if unobserved factors also vary across levels of the instrumental variable, and by a sufficient magnitude to explain our findings. Because Aboriginal populations tend to be larger in regions with a higher proportion of family physicians, and their cesarean delivery rates tend to be lower, unobserved variables varying in a similar pattern would tend to lessen the effect we observed.

Finally, the data we used are generally accurate for clinically significant diagnoses and procedures, ${ }^{15,16}$ and, perhaps most important for this study, a variable for prior cesarean delivery was included in the database. However, parity was not captured, and there may be variation in this factor between women 
cared for by family physicians and by obstetricians. In addition, although several categories of obesity are captured in the database, it is unclear how complete or accurate these data are.

\section{Conclusion}

We found a large discrepancy between logistic and instrumental-variable-adjusted estimates of the risk of cesarean delivery among family physicians versus obstetricians. This suggests that clinical and/or sociocultural factors affecting the decision to perform a cesarean delivery are missing from our database and that there is variability in these factors between women cared for by family physicians and by obstetricians. Family physicians may have higher cesarean delivery rates relative to obstetricians than previously thought, but these results should be interpreted with caution.

\section{References}

1. Marshall JL, Spiby H, McCormick F. Evaluating the 'Focus on Normal Birth and Reducing Caesarean section Rates Rapid Improvement Programme': a mixed method study in England. Midwifery 2015;31:332-40.

2. Deneux-Tharaux C, Carmona EF, Bouvier-Colle MF, et al. Postpartum maternal mortality and cesarean delivery. Obstet Gynecol 2006;108:541-8.

3. Blanchette $\mathrm{H}$. The rising cesarean delivery rate in America: What are the consequences? Obstet Gynecol 2011;118:687-90.

4. Liu S, Liston RM, Joseph KS, et al.; Maternal Health Study Group of the Canadian Perinatal Surveillance System. Maternal mortality and severe morbidity associated with low-risk planned cesarean delivery versus planned vaginal delivery at term. CMA7 2007;176:455-60.

5. Appropriate technology for birth. Lancet 1985;2:436-7.

6. Health indicators 2013. Ottawa: Canadian Institute for Health Information; 2013.

7. King TL. Preventing primary cesarean sections: intrapartum care. Semin Perinatol 2012;36:357-64.

8. Harris SJ, Janssen PA, Saxell L, et al. Effect of a collaborative interdisciplinary maternity care program on perinatal outcomes. CMA7 2012;184:1885-92.

9. Walters D, Gupta A, Nam AE, et al. A cost-effectiveness analysis of low-risk deliveries: a comparison of midwives, family physicians and obstetricians. Healthc Policy 2015;11:61-75.

10. Avery DM Jr, Graettinger KR, Waits S, et al. Comparison of delivery procedure rates among obstetrician-gynecologists and family physicians practising obstetrics. Am 7 Chin Med 2014;10:16-20.

11. Nicholson JM. Risk adjustment in maternity care: the use of indirect standardization. Int 7 Womens Health 2010;2:255-62.

12. Tracy SK, Welsh A, Hall B, et al. Caseload midwifery compared to standard or private obstetric care for first time mothers in a public teaching hospital in Australia: a cross sectional study of cost and birth outcomes. BMC Pregnancy Childbirth 2014:14:46.

13. Li Y, Townend J, Rowe R, et al. The effect of maternal age and planned place of birth on intrapartum outcomes in healthy women with straightforward pregnancies: secondary analysis of the Birthplace national prospective cohort study. BM7 Open 2014;4:e004026.

14. Stukel TA, Fisher ES, Wennberg DE, et al. Analysis of observational studies in the presence of treatment selection bias: effects of invasive cardiac management on AMI survival using propensity score and instrumental variable methods. 7AMA 2007;297:278-85.

15. Joseph KS, Fahey J; Canadian Perinatal Surveillance System. Validation of perinatal data in the Discharge Abstract Database of the Canadian Institute for Health Information. Cbronic Dis Can 2009;29:96-100.

16. CIHI Data Quality Study of the 2007-2008 Discharge Abstract Database. Ottawa: Canadian Institute for Health Information; 2010.

17. Wen SW, Huang L, Liston R, et al.; Maternal Health Study Group, Canadian Perinatal Surveillance System. Severe maternal morbidity in Canada, 1991-2001. CMA7 2005;173:759-64.

18. Joseph KS, Liu S, Rouleau J, et al. Severe maternal morbidity in Canada, 2003 to 2007: surveillance using routine hospitalization data and ICD-10CA codes. 7 Obstet Gynaecol Can 2010;32:837-46.

19. Joseph KS, Rouleau J, Kramer MS, et al.; Maternal Health Study Group of the Canadian Perinatal Surveillance System. Investigation of an increase in postpartum haemorrhage in Canada. B7OG 2007;114:751-9.

20. Kramer MS, Rouleau J, Baskett TF, et al.; Maternal Health Study Group of the Canadian Perinatal Surveillance System. Amniotic-fluid embolism and medical induction of labour: a retrospective, population-based cohort study. Lancet 2006;368:1444-8.

21. Wen SW, Rusen ID, Walker M, et al.; Maternal Health Study Group, Canadian Perinatal Surveillance System. Comparison of maternal mortality and morbidity between trial of labor and elective cesarean section among women with previous cesarean delivery. Am 7 Obstet Gynecol 2004;191:1263-9.

22. Aubrey-Bassler K, Newbery S, Kelly L, et al. Maternal outcomes of cesarean sections: Do generalists' patients have different outcomes than specialists' patients? Can Fam Physician 2007;53:2132-8.

23. Health Canada. Canadian perinatal health report 2003. Ottawa: Minister of Public Works and Government Services Canada; 2003.

24. Canadian perinatal health report. 2008 ed. Ottawa: Public Health Agency of Canada; 2008

25. Health Canada. Special report on maternal mortality and severe morbidity in Canada - enhanced surveillance: the path to prevention. Ottawa: Minister of Public Works and Government Services Canada; 2004.

26. Wilkins R, Khan S. PCCF + version H user's guide. Automated geographic coding based on the Statistics Canada Postal Code Conversion Files, including postal codes through October 2010. Cat. no. 82F0086-XDB. Ottawa: Health Analysis Division, Statistics Canada; 2011.

27. Phibbs CS, Baker LC, Caughey AB, et al. Level and volume of neonatal intensive care and mortality in very-low-birth-weight infants. N Engl 7 Med 2007;356: 2165-75.

28. Goodman DC, Fisher ES, Little GA, et al. The relation between the availability of neonatal intensive care and neonatal mortality. N Engl 7 Med 2002;346: $1538-44$.

29. Aubrey-Bassler K, Cullen RM, Simms A, et al. Outcomes of deliveries by family physicians or obstetricians: a population-based cohort study using an instrumental variable. CMA7 2015;187:1125-32.

30. QuickStats - Discharge Abstract Database/Hospital Morbidity Database: childbirth indicators by place of residence. Ottawa: Canadian Institute for Health Information; 2017. Available: https://apps.cihi.ca/mstrapp/asp/Main aspx?Server=apmstrextprd_i\&project=Quick\%20Stats\&uid=pce_pub_en\&pwd $=\&$ evt $=2048001 \&$ visualization Mode $=0 \&$ documentID $=029 \mathrm{DB} 170438205 \mathrm{AEB}$ CC75B8673CCE822 (accessed 2017 Aug. 15).

31. Dartmouth Atlas of Health Care [main page]. Lebanon (NH): Dartmouth Institute for Health Policy and Clinical Practice; 2012; Available: www. dartmouthatlas.org/ (accessed 2014 Nov. 15)

32. Canadian Classification of Health Interventions (CCI). Vol. 3: Tabular list. Ottawa: Canadian Institute for Health Information; 2009.

33. Palmer TM, Sterne JAC, Harbord RM, et al. Instrumental variable estimation of causal risk ratios and causal odds ratios in Mendelian randomization analyses. Am 7 Epidemiol 2011;173:1392-403.

34. Brookhart MA, Rassen JA, Schneeweiss S. Instrumental variable methods in comparative safety and effectiveness research. Effective Health Care Research Report No. 22. Rockville (MD): Agency for Healthcare Research and Quality; 2010.

35. Clarke PS, Windmeijer F. Instrumental variable estimators for binary outcomes. 7 Am Stat Assoc 2012;107:1638-52.

36. Norton EC, Miller MM, Kleinman LC. Computing adjusted risk ratios and risk differences in Stata. Stata 7 2013;13:492-509.

37. Stock JH, Yogo M. Testing for weak instruments in linear IV regression. Identification and inference for econometric models: essays in honor of Thomas Rothenberg, 2005. Rochester (NY): Social Science Research Network; 2005. Available: https://ssrn.com/abstract=1734933 (accessed 2015 Mar. 15).

38. Fang G, Brooks JM, Chrischilles EA. Comparison of instrumental variable analysis using a new instrument with risk adjustment methods to reduce confounding by indication. Am 7 Epidemiol 2012;175:1142-51.

Affiliations: Discipline of Family Medicine (Dawe, Bishop, Pendergast, Avery, Monaghan, Duggan, Aubrey-Bassler) and Primary Healthcare Research Unit (Aubrey-Bassler), Memorial University of Newfoundland, St. John's, Nfld.

Contributors: Russell Dawe was the Principal Investigator. He and Kris Aubrey-Bassler conceived and designed the study. Kris Aubrey-Bassler acquired and analyzed the data. Russell Dawe, Kelly Monaghan and Kris Aubrey-Bassler drafted the manuscript. All of the authors contributed to data interpretation, revised the manuscript for important intellectual content, gave final approval of the version to be published and agreed to be accountable for all aspects of the work.

Funding: Funding for this study was provided to the research team through the Dr. A.R. Cox Research Grant via the Medical Research Endowment Fund at Memorial University of Newfoundland. The research reported was conducted independently of the funder.

Disclaimer: Parts of this article are based on data and information provided by the Canadian Institute for Health Information (CIHI). The analyses, conclusions, opinions and statements expressed herein are those of the authors and not those of the CIHI.

Supplemental information: For reviewer comments and the original submission of this manuscript, please see www.cmajopen.ca/content/5/4/ E823/suppl/DC1. 